\title{
Suction force of blowing fans on various surface shapes of outer wall
}

\author{
Young-Bog Ham ${ }^{1}$, Byung-Ju Lim ${ }^{2 *}$, Jong-Ho Noh ${ }^{3}$, Jong-Ho Park ${ }^{3}$ \\ ${ }^{1}$ Extreme Mechanical Engineering Research Division, Korea Institute of Machinery and \\ Materials, Korea \\ ${ }^{2}$ Environment and Energy Systems Research Division, Korea Institute of Machinery and \\ Materials, Korea \\ ${ }^{3}$ Department of Mechanical Engineering, Chungnam National University, Korea \\ *Corresponding author (bzoo77@kimm.re.kr)
}

\begin{abstract}
Purpose The outer walls of high-rise buildings contain many grooves of irregular shapes and sizes. Conventionally, gondola systems on platforms are used to carry the workers who conduct maintenance work on the outer walls of highrise buildings. It is very difficult to perform such works on outer walls using a gondola due to external disturbances such as squalls. Therefore we propose a stable attachment for a grooved wall surface; with an air suction force of a fan it is possible to generate enough force to attach onto the wall surface. In this paper, a test apparatus was developed to measure the attaching force of a suction fan according to fan speed. Also, the suction forces were measured according to four types of wall surfaces. Method A test rig for suction force was developed to measure the attaching force of the suction fan. Using this test rig, four kinds of specimens were compared by measuring the attaching force. The test rig consisted of a pneumatic cylinder, a load-cell, and a rotating speed meter. Four different vertical walls surfaces were made: flat, step, rib and embossing type surfaces. The suction fan housing was fixed by a frame when the fan rotated. The wall specimen was moved by a pneumatic cylinder, and then the separation force was measured using a load cell. For each of the vertical wall types the attaching force of the suction fan was measured at varying the rotation speeds. Results The maximum attachment force of the suction fan was 3.2 times higher on the flat surface than on the step surface at $700 \mathrm{rpm}, 1.3$ times higher on the embossed surface at $1400 \mathrm{rpm}$, and 1.3 times higher on both flat and rib surface at $1800 \mathrm{rpm}$. The maximum attachment force increased linearly according to the motor rotating speed. These results clearly show that the attachment performance of the fan is considerably less influenced by the groove of surface than by increases in the fan rotation speed.
\end{abstract}

Keywords: suction, suction fans, high-rise building, vertical outer wall, test rig, gondola cage

\section{INTRODUCTION}

Typically, most robots vertically moving or climbing in concrete wall or glass have used the vacuum force to grab on surface of the wall. Many researchers have been developing on robot travelling and working on the vertical surface, and the robots are practically used attaching force of suction pads to attach the wall. Dong Gwang L., et al. developed and tested a robot system using vacuum suction technology for cleaning the window panes of a building's outer walls ${ }^{1}$. Kun Chan S., et al. designed a suction unit for a robot system which can climb up irregular vertical surfaces ${ }^{2}$. Siyoul $\mathrm{J}$ conducted a study on the design of a vacuum suction pad which can provide a uniform contact shape in large-scale imprinting ${ }^{3}$. Guido La Rosa et al. developed a low-cost and light weight robot system which can travel in a vertical direction using eight suction cups ${ }^{4}$. The NINJYA BIPED developed by Nishi al Miyazaki can travel along a wall's surface using small suction cups ${ }^{5-7}$. Hwang Kim et al. developed a robot system which can travel along vertical walls stably and continuous- ly, using endless tracks attached with vacuum pads ${ }^{8}$. However, robots traveling on vertical walls have limitations in terms of the shape of the walls and their adhesive force ${ }^{9-11}$. The vacuum suction pads used in preceding studies for movement and works on vertical walls are lightweight, making them easy to use in various applications. However, attaching performance of the vacuum pad for grooved surfaces might be lower comparing with flat surface ${ }^{12}$.

Surfaces of buildings require cyclical maintenance such as repair, cleaning and painting. Normally, gondola systems boarding the workers have been used as maintenance tool on the buildings. However, as the building's height is recently higher, working risk also rises and the maintenance robot of gondola type is needed to be developed. Because the gondola easily tends to sway around in the wind, it is difficult for the robot to carry out precision works such as painting. Even in an environment without an external load such as wind, the gondola platform has to be fixed onto a surface to perform such works as sweeping or painting. To perform these kinds of work on outer walls using gondolas, stable attachment 
force to the wall is required, taking into consideration the external loads and self-load. Though suction pads used in above-mentioned papers is possible to be applied to an attaching tool on the vertical surface, in various surfaces of the latest buildings, especially in grooved walls, suction force of the pads is not always steady.

A fan has been largely installed in pipe line or duct to control the air circulation and the heat. Air suction force of the fan is possible to use attaching force on the wall surface.

In this paper, to verify performance of the fan instead of vacuum pad as attaching unit of vertical wall, a test apparatus was developed to measure the attaching forces of suction fan. Four types of wall surface shapes are fabricated to test the performance of the fans in the grooved surface. And, the suction forces of two suction fans which have different housing shape and similar motor capacity were measured and analyzed.

\section{WALL SAMPLES}

To simulate the various wall shapes of high-rise buildings, four types of wall samples - including flat, step, rib, and embossing shapes- were prepared. The grooved wall samples were fabricated as shown in Fig. 1. Sample size for the suction fan is 980 $\mathrm{mm}(\mathrm{H}) \times 980 \mathrm{~mm}(\mathrm{~L}) \times 70 \mathrm{~mm}(\mathrm{D})$. In case of step, rib and embossing type specimen, groove depth is 30 $\mathrm{mm}$. In case of rib and embossing type specimen, distance of embossed and engraved part is $40 \mathrm{~mm}$. Otherwise, sample size for the vacuum pad is 500 $\mathrm{mm}(\mathrm{H}) \times 500 \mathrm{~mm}(\mathrm{~L}) \times 50 \mathrm{~mm}(\mathrm{D})$. In case of rib, the distance of embossed and engraved part is $40 \mathrm{~mm}$. For embossing type, distances of embossed and engraved part are respectively $40 \mathrm{~mm}$ and $20 \mathrm{~mm}$.

\section{TEST EQUIPMENT}

Test apparatus to measure attaching force of the suction fan on concrete sample surface was manufactured. Main components of the apparatus compose of pneumatic cylinder, load cell, and concrete wall as presented in Fig. 2. Actual manufactured test equipment shows in Fig. 3. The specifications of the sub-components of the test equipment are presented in Table 1.
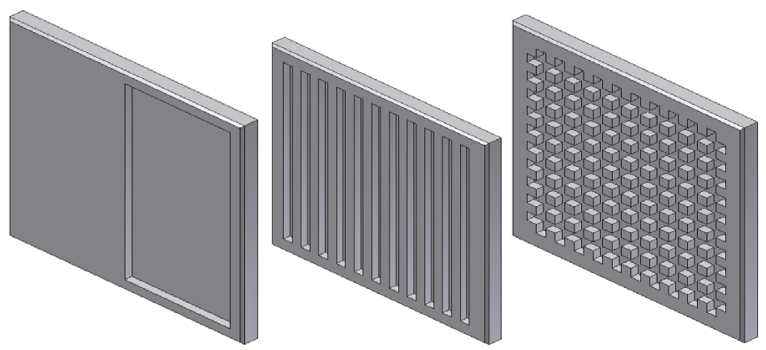

Fig.1. Shapes of wall surfaces. (a) Step. (b) Rib. (c) Embossing
The fan is installed in the fan-housing which is fixed by metal frame. The pneumatic cylinder, which also is fixed by metal frame, functions as traveling the wall sample in the vertical direction against the suction fan. If the wall moves by the cylinder under the condition the suction fan is absorbed on the wall, load cell between the wall and cylinder is loaded to tensile force. And calculating load value of load cell is same as suction force of the fan.

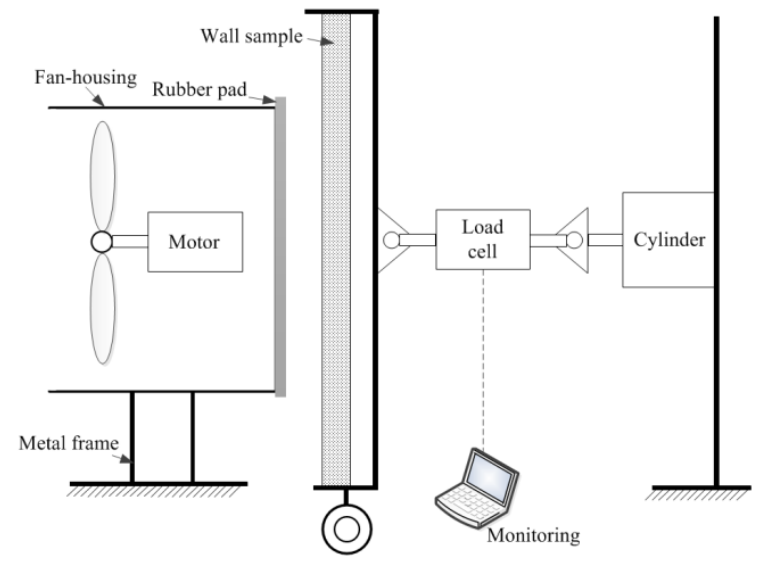

Fig.2. Schematics of test equipment for suction fan

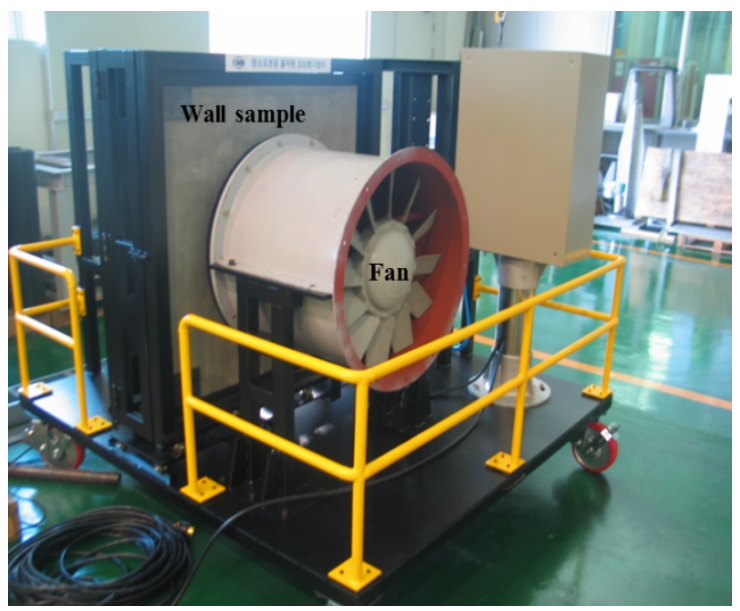

Fig.3. Test equipment for suction fan

Table 1. Specifications of the sub-components

\begin{tabular}{|c|l|}
\hline Contents & \multicolumn{1}{|c|}{ Specifications } \\
\hline Load cell & Range: max. $2,000 \mathrm{~N}$ \\
\hline $\begin{array}{c}\text { Pneumatic } \\
\text { Cylinder }\end{array}$ & Max pressure : $1 \mathrm{MPa}$ \\
\hline Compressor & Max. pressure: $1 \mathrm{MPa}$ \\
\hline $\mathrm{DAQ}$ & Model: NI SCXI $1520(8 \mathrm{ch})$ \\
\hline
\end{tabular}



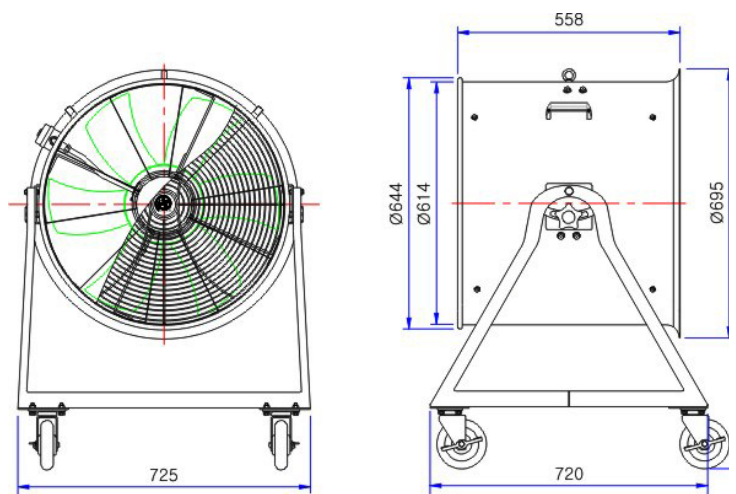

Fig.4.Dimension of A-type suction fan

Two types of the suction fans are applied to the test apparatus. A-type suction fan has the fan-housing of cylinder shape with diameter of about $600 \mathrm{~mm}$, and the rubber pad is installed in the rim of the fanhousing and functions as buffer from the wall when contacting as shown in Fig. 4. The maximum rotating speed of the fan is $1,800 \mathrm{rpm}$. B-type suction fan has the fan-housing of cylinder shape with diameter of $614 \mathrm{~mm}$, but the end shape of the fan-housing is a square $667 \mathrm{~mm}$ on a side as shown in Fig. 5. The square end has rigid brush of $100 \mathrm{~mm}$ length unlike A-type. The maximum rotating speed of the fan is $1,725 \mathrm{rpm}$.

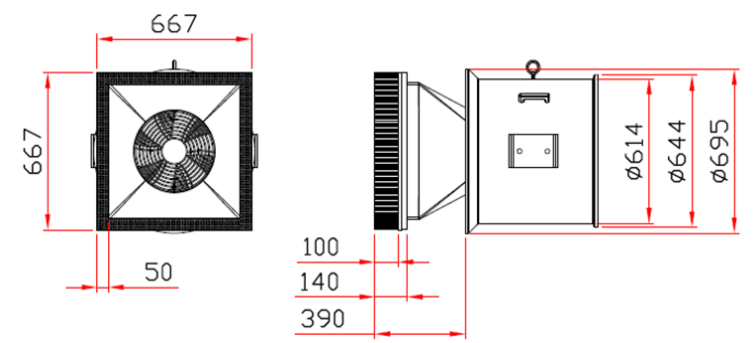

Fig.5. Dimension of B-type suction fan

\section{TEST PROCEDURE}

The suction performance test of the fans was conducted according to the following procedures: 1) Install the suction fan and wall specimen 2) Operate the suction fan after regulating fan rotating speed. 3) Move the concrete wall sample to fan-housing using the pneumatic cylinder. 4) Attach the fan-housing to wall surface by suction force of the fan. 5) Move the sample in the reverse direction of fan-housing by injecting compressed air into the cylinder. 6) Increase the air pressure in cylinder until detaching completely the sample from the fan-housing. 7) Repeat the test on regulating fan speed and changing the surface walls.

During the test, measuring values for load between cylinder and wall, cylinder air pressure, and displacement of wall specimen from the wall are continuously monitoring and saving to the computer.

\section{TEST RESULT}

The maximum suction forces of the two fans for each surface sample with motor rotating speed are shown in Fig. 6. The maximum suction force of A-type is $231.9 \mathrm{~N}$ with flat and rib type in $1,800 \mathrm{rpm}$, and Btype is $142 \mathrm{~N}$ with flat and rib type in $1,725 \mathrm{rpm}$. The maximum forces per area of the fan for the four samples that is flat, step, rib, and embossing type are respectively $820.2 \mathrm{~N} / \mathrm{m}^{2}, 630.3 \mathrm{~N} / \mathrm{m}^{2}, 820.2 \mathrm{~N} / \mathrm{m}^{2}$, and $708.1 \mathrm{~N} / \mathrm{m}^{2}$ for A-type and $324.9 \mathrm{~N} / \mathrm{m}^{2}, 313.4$ $\mathrm{N} / \mathrm{m}^{2}, 337.5 \mathrm{~N} / \mathrm{m}^{2}$, and $319.6 \mathrm{~N} / \mathrm{m}^{2}$ for B-type. Results on the maximum suction force per area are presented in Fig. 7. The maximum suction force for each surface sample increased linearly with rotating speed. An Average of the maximum suction forces per area for all the samples in same rotating speed is $90.5 \mathrm{~N} / \mathrm{m}^{2}$ in $700 \mathrm{rpm}, 494.4 \mathrm{~N} / \mathrm{m}^{2}$ in $1400 \mathrm{rpm}$, and $744.7 \mathrm{~N} / \mathrm{m}^{2}$ in $1800 \mathrm{rpm}$ for A-type as presented in Table 2, and $167.5 \mathrm{~N} / \mathrm{m}^{2}$ in $863 \mathrm{rpm}, 225.3 \mathrm{~N} / \mathrm{m}^{2}$ in $1,294 \mathrm{rpm}, 250.1 \mathrm{~N} / \mathrm{m}^{2}$ in $1,438 \mathrm{rpm}$ and $306.3 \mathrm{~N} / \mathrm{m}^{2}$ in 1,725 rpm for B-type as presented in Table 3.

\section{CONCLUSION}

In this study, testing equipment was constructed respectively to test and measure the attachment performance of two suction fans on various configurations of wall surface, i.e., flat, step, rib, and embossing types, formed with concrete material. The attachment performance means a degree of withstanding on the surface against external force, and is evaluated by measuring tensile force of the load cell when the fan attaching on the surface is detached by the air cylinder.

The testing equipment was designed to allow to change of the concrete wall sample and to measure both the vertical and horizontal attachment forces. The maximum suction force of A-type suction fan is 1.6 times higher than B-type. In case of A-type, a change of the maximum suction force with rotating speed is greater than B-type, and so do the change of the maximum suction force with surface shapes.

In two result graphs of Fig. 6, the slope of A-type is 2.23 times greater than B-type in flat surface. Especially, the maximum standard deviation for data of the maximum suction force is 1,043 for A-type and is 144.8 for B-type. These results show that though Atype fan is possible to get a higher suction force than B-type, it is difficult to stable suction force for various surface shapes. If the regular suction force is needed on the building outer-wall work without reference, B-type suction fan is the better for it. On flat surface,

B-type suction fan could get always the maximum suction force, average maximum suction force decreased according to order of flat, rib, step and embossing shape. The results showed the fan suction force decrease as the gap of contact parts between the wall surface and the fan housing is larger. 


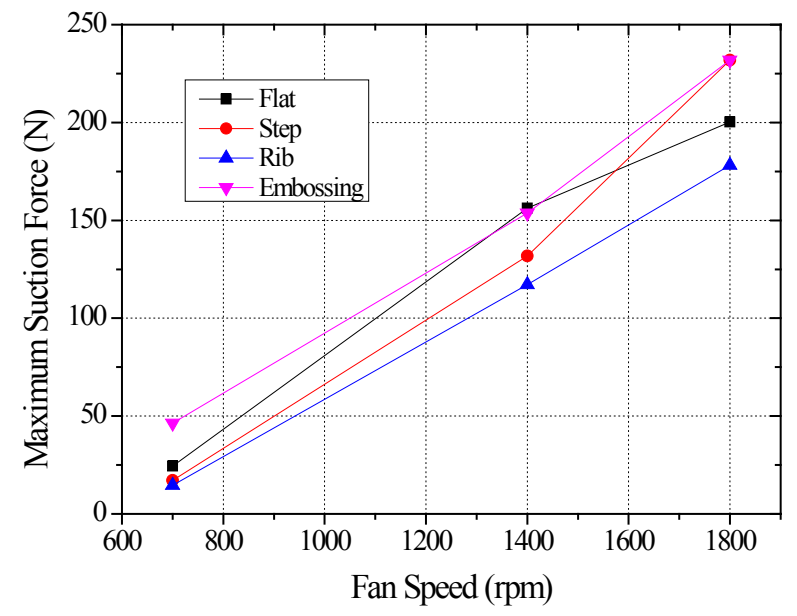

(a) A-type

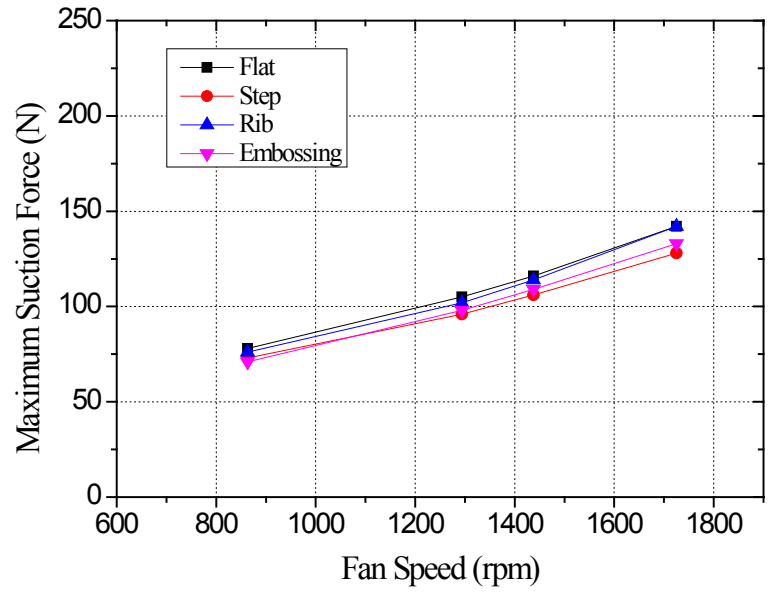

(b) B-type

Fig. 6. Maximum suction force for suction fan

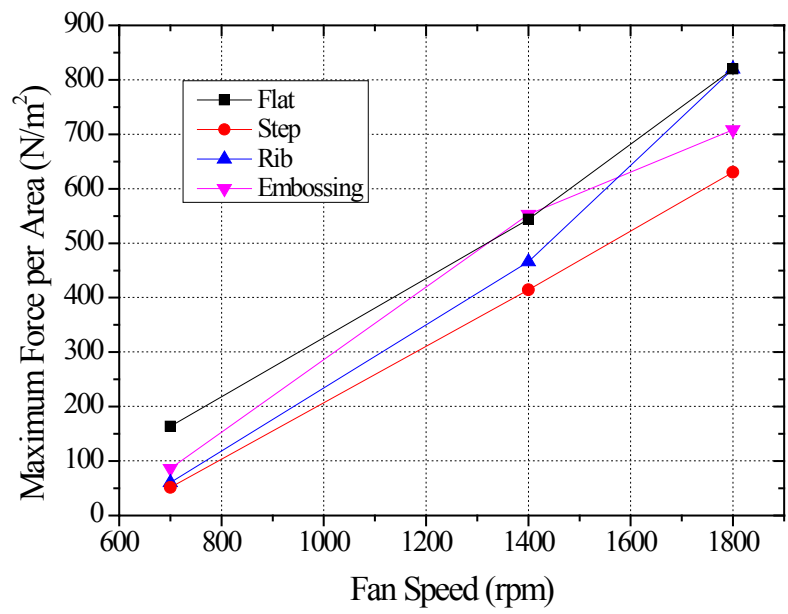

(a) A-type

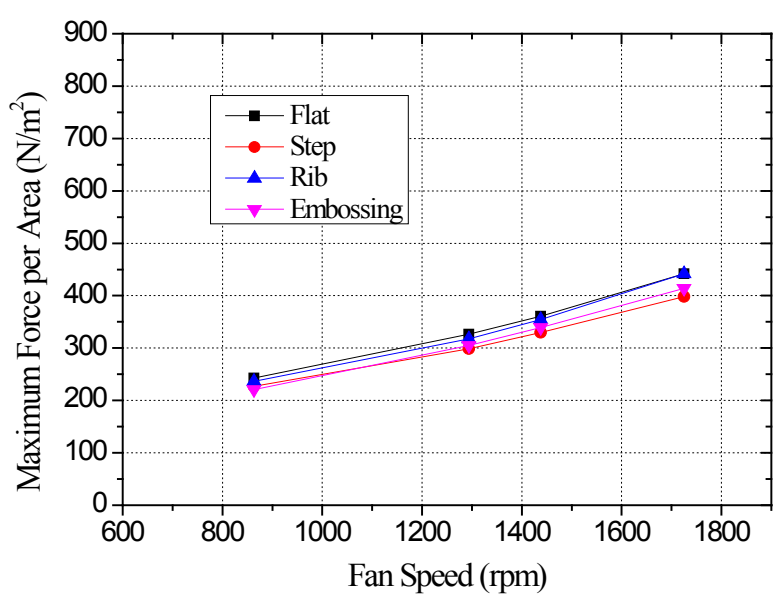

(b) B-type

Fig. 7. Maximum suction force per area for suction fan

Table 2. Test results of A-type fan

\begin{tabular}{|c|c|c|c|c|c|c|}
\hline Wall shape & Flat & Step & Rib & Embossing & Maximum & Average \\
\cline { 1 - 5 } & 46.3 & 14.6 & 17.1 & 24.4 & Flat & 25.6 \\
\hline 1,400 & 153.8 & 117.2 & 131.8 & 156.3 & Embossing & 139.8 \\
\hline 1,800 & 231.9 & 178.2 & 231.9 & 200.2 & Flat \& Rib & 210.6 \\
\hline Average & 144.0 & 103.33 & 126.93 & 126.97 & & - \\
\hline Slope & 0.167 & 0.148 & 0.192 & 0.163 & & - \\
\hline
\end{tabular}

Table 3. Test results of B-type fan

\begin{tabular}{|c|c|c|c|c|c|c|}
\hline Fan Speed & Flat & Step & Rib & Embossing & Maximum & Average \\
\hline 863 & 78 & 73 & 76 & 71 & Flat & 74.5 \\
\hline 1,294 & 105 & 96 & 102 & 98 & Flat & 100.3 \\
\hline 1,438 & 116 & 106 & 114 & 109 & Flat & 111.3 \\
\hline 1,725 & 142 & 128 & 142 & 133 & Flat and Rib & 136.3 \\
\hline Average & 110.25 & 100.75 & 108.50 & 102.75 & & - \\
\hline
\end{tabular}


The results disclosed in this paper could serve useful information when determining the specifications of suction fan or vacuum pad to be used in gondola or robot systems for work on a building's outer walls. However, further tests should be conducted about horizontal attachment force or attachment force with change of load rate in suction fan for various performance evaluations of attachment tools.

\section{ACKNOWLEDGMENT}

The work presented in this paper was funded by the BMRC (Building-Façade Maintenance Robot Research Center), and supported by the Korea Institute of Construction and Transportation Technology Evaluation and Planning (KICTEP) under the Ministry of Land, Transport and Maritime Affairs (MLTM).

\section{References}

1. Dong-Kwang L. et al, "An instrument of building an outer-wall window-cleaning robot and controller layout using vacuum adsorption technology", pp. 259260, 2007.

2. Kunchan S. et al, "Design of an attachment device for robotic systems that climb rugged vertical surfaces", KSPE, pp. 99-100, 2007.

3. Jang, S., "A study on the enhancement of uniform contact technology for large-scale imprinting with the design of a vacuum gripping pad", Journal of the KSTLE, 2008, Vol. 24(6), 623-331, 1999.

4. Rosa, G. la, Messina, M., Muscato, G., Sinatra, R., "A low-cost lightweight climbing robot for the inspection of vertical surfaces", Mechatronics, Vol 12, pp. 71-96, 2002.
5. Nishi, A., "A biped walking robot capable of moving on a vertical wall", Mechatronics, Vol. 2(6), pp. 543554, 1992.

6. Nishi, A., "Development of wall-climbing robots", Compute Electron Eng, Vol. 22(2), pp. 123-149, 1996.

7. Nishi, A., Miyagi, H., "A wall climbing robot using the thrust force of a propeller mechanism and control in a strong wind", JSME Int J Ser C, Vol. 1(37), pp. 172-178, 1994.

8. Kim, H., Kim, D., Yang, H., Lee, K., Seo, K., Chang, D., Kim, J., "A wall climbing robot with a vacuum caterpillar wheel system operated by a mechanical valve", Proceedings of the $9^{\text {th }}$ International Conference on Climbing and Walking Robots, pp. 28-33, 2006.

9. Elliot, M., Norris, W., Xiao, J., "City-Climber: A new generation of wall-climbing robots", Proceedings of the IEEE International Conference on Robotics and Automation, 2007.

10. Hirose, S., Nagakubo, A., Toyama, R., "A machine that can walk and climb on floors, walls and ceilings", International Conference on Advanced Robotics, Vol. 1, pp. 753-758, 1991.

11. Asbeck, A.T., Kim, S., Cutkosky, M.R., Provancher, W.R., Lanzetta, M., "Scaling hard vertical surfaces with compliant microspine arrays", The International Journal of Robotic Research, Vol. 25, pp. 11651179, 2006.

12. Lim, B-J., "A preliminary experiment for a fastening equipment design on the vertical wall of high-rise buildings", The International Conference on Japan Fluid Power 2011. 